Article

\title{
Background Glucocorticoid Therapy Has No Impact on Efficacy and Safety of Abatacept or Adalimumab in Patients with Rheumatoid Arthritis
}

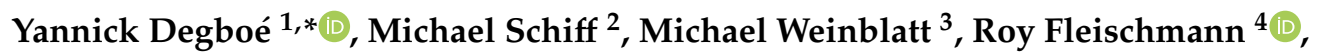 \\ Harris A. Ahmad ${ }^{5}$ and Arnaud Constantin ${ }^{1}$ \\ 1 Rheumatology Centre, Toulouse University Hospital and University Toulouse III Paul Sabatier, \\ 31059 Toulouse, France; constantin.a@chu-toulouse.fr \\ 2 Rheumatology Division, University of Colorado, Denver, CO 80111, USA; michael.schiff@me.com \\ 3 Department of Rheumatology \& Immunology, Brigham and Women's Hospital, Boston, MA 02115, USA; \\ mweinblatt@bwh.harvard.edu \\ 4 Department of Internal Medicine, University of Texas Southwestern Medical Center, Metroplex Clinical \\ Research Center, Dallas, TX 75231, USA; RFleischmann@arthdocs.com \\ 5 Immunology, Bristol-Myers Squibb, Princeton, NJ 08540, USA; Harris.Ahmad@bms.com \\ * Correspondence: degboe.y@chu-toulouse.fr
}

Received: 20 May 2020; Accepted: 22 June 2020; Published: 26 June 2020

check for updates

\begin{abstract}
To date, the impact of background glucocorticoids (GC) on the efficacy and safety of abatacept or adalimumab in patients with active rheumatoid arthritis (RA) is not clearly established. This post hoc analysis of (AMPLE) trial (NCT00929864) compared efficacy and safety outcomes over 2 years in patients treated with abatacept or adalimumab plus background methotrexate (MTX), who continued GC ( $\leq 10 \mathrm{mg} /$ day) versus those who were not receiving GC (no-GC). Of 646 randomized patients, 317 received abatacept + MTX (161 GC, 156 no-GC) and 326 received adalimumab + MTX (162 GC, 164 no-GC). At Year 2, the adjusted mean changes from baseline in Disease Activity Score (DAS28 C-reactive protein (CRP)) and Health Assessment Questionnaire-Disability Index (HAQ-DI) were not significantly different in the GC versus no-GC subgroups receiving abatacept or adalimumab. A similar proportion of patients achieved remission, HAQ-DI score improvement $\geq 0.3$ and radiographic progression rates. No clinically meaningful safety differences were observed between GC versus no-GC subgroups either with abatacept or adalimumab. In patients with active RA of similar baseline disease activity treated with abatacept or adalimumab plus background MTX, there was no additional value of background GC on clinical, functional or radiographic outcomes over two years.
\end{abstract}

Keywords: disease activity; rheumatoid arthritis; biologic DMARDs

\section{Introduction}

Current guidelines for rheumatoid arthritis (RA) treatment suggest the use of glucocorticoids (GCs) in combination with disease-modifying antirheumatic drugs (DMARDs) at the initiation of therapy, but to use the lowest dose for the shortest period of time necessary [1,2]. However, considerable debate remains regarding dose, timing and duration of use [1-4]. Although GCs can be effective in decreasing the signs and symptoms of RA, and reducing radiographic progression [2,5-7], they may be associated with a range of adverse effects including osteoporosis, hyperglycemia/diabetes mellitus, cardiovascular events and infections $[3,5,6]$.

Abatacept, a T-cell co-stimulation modulator is approved for the treatment of active RA in adults and has been shown to be similarly effective as adalimumab in patients who have active disease 
despite methotrexate (MTX) therapy [8]. A head-to-head Abatacept versus adaliMumab comparison in biologic-naïve RA subjects with background methotrexate (AMPLE) trial (ClinicalTrials.gov: NCT00929864) showed similar efficacy and tolerability for subcutaneous (SC) abatacept versus the TNF inhibitor adalimumab over two years in patients with active RA and an inadequate response to MTX [8,9]. The trial design allowed enrollment of patients on stable, background GC therapy of $\leq 10 \mathrm{mg}$, which had to be maintained at a stable dose for the duration of the two-year study. Patients were not allowed to initiate GCs or reduce or discontinue GCs for reasons other than safety during the study.

Biological (bDMARDs) or targeted synthetic DMARDs (tsDMARDs) randomized controlled trials providing published data about the impact of background GC therapy on clinical and radiological outcomes in RA, are scarce [10-13]. The objective of this post hoc analysis of the AMPLE trial was to assess whether there was an impact of background GCs at doses of $\leq 10 \mathrm{mg} /$ day (prednisone equivalent) on the efficacy and safety of SC abatacept or SC adalimumab in biologic-naïve patients with active RA and an inadequate response to MTX. We compared patients with active disease at baseline despite background GCs with those who had similar disease activity but did not receive GCs.

\section{Experimental Section}

\subsection{Study Design and Analysis Population}

The full study design, ethics approvals, study population, inclusion and exclusion criteria and primary results of the AMPLE trial have been described previously $[8,9]$. Briefly, biologic-naïve patients were randomized 1:1 to receive SC abatacept $125 \mathrm{mg}$ weekly or SC adalimumab $40 \mathrm{mg}$ once every 2 weeks, both in combination with stable MTX for the duration of the trial. In addition, patients were allowed to continue stable, background GCs $\leq 10 \mathrm{mg}$ per day, without change in dose other than for safety reasons.

In AMPLE, all efficacy and safety analyses were performed using the intent-to-treat population, which included all patients who were randomized and received at least one dose of study drug. This post hoc analysis compared clinical, functional and radiographic efficacy outcomes in two subpopulations of patients treated with abatacept plus MTX or adalimumab plus MTX: those who continued stable, background GCs ( $\leq 10 \mathrm{mg} /$ day) and those who received no GC therapy (no-GC) during the study.

\subsection{Ethics Approval}

The AMPLE study was approved by the institutional review boards and independent ethics committees at the participating sites (approval of the protocol: 09-5289-0). The study was conducted in accordance with the Declaration of Helsinki and was consistent with the International Conference on Harmonization and Good Clinical Practice.

\subsection{Outcome Measures}

Patient demographics and disease characteristics were analyzed at baseline by treatment and cohort. Clinical, functional and radiographic outcomes were assessed at baseline and at multiple intervals up to Year 2 (Day 729) of the blinded treatment period. Outcomes included the adjusted mean change from baseline in Disease Activity Score in 28 joints (C-reactive protein) (DAS28 (CRP)), Health Assessment Questionnaire-Disability Index (HAQ-DI) and modified total Sharp score (mTSS) at Years 1 and 2. The proportion of patients achieving remission according to Clinical Disease Activity Index (CDAI) and Simplified Disease Activity Index (SDAI) criteria, and the proportion of patients achieving DAS28 (CRP) < 2.6, with improvement in HAQ-DI score $\geq 0.3$, and with radiographic nonprogression (mTSS $\leq$ smallest detectable change (2.2 points) [14]) were also assessed at Years 1 and 2. Safety events were classified using the Medical Dictionary for Regulatory Activities. 


\subsection{Statistical Analysis}

All randomized and treated patients were included in the analysis. Baseline patient demographics and disease characteristics were analyzed descriptively by treatment for each cohort. For mean change in DAS28 (CRP) scores, HAQ-DI scores and ACR core component scores, missing values were imputed using a last observation carried forward analysis. For patients who discontinued between years 1 and 2, radiographs were obtained at an early termination visit. In these patients, the 2-year data were imputed using linear extrapolation based on assessments performed at baseline and at the time of discontinuation. Subjects without baseline radiographs were excluded from all radiographic analyses [9]. Adjusted mean changes from baseline in disease activity measures were determined, with corresponding 95\% confidence intervals (CIs), at each time point by treatment for each cohort. Endpoints were compared between the cohort of patients who continued background GC therapy and those who were not receiving GC at baseline in each treatment group using a chi-square test for categorical variables and an analysis of covariance model controlling for baseline covariates and DAS28 (CRP) stratification for continuous variables.

\section{Results}

\subsection{Patient Population}

In total, 646 patients were randomly assigned to receive treatment in the AMPLE trial (abatacept, $n=318$; adalimumab, $n=328$ ) [8], of whom 252 abatacept- and 245 adalimumab-treated patients completed Year 2 [9]. The current post hoc analysis included 317/318 abatacept- and 326/328 adalimumab-treated patients. Three patients ( 1 abatacept and 2 adalimumab) were excluded due to a baseline GC dose $>10 \mathrm{mg}$. Of the abatacept- and adalimumab-treated patients, 161 and 162, respectively, were on stable background GC at study baseline and 156 and 164, respectively, were not and were not subsequently treated with GC during the study. Baseline demographics and disease activity were similar across all subgroups (Table 1), other than higher baseline mTSS scores in patients on background GC compared with the no-GC subgroup.

Table 1. Baseline demographics and disease characteristics of patients.

\begin{tabular}{ccccc}
\hline & \multicolumn{2}{c}{ SC Abatacept + MTX $(n=318)$} & \multicolumn{2}{c}{ SC Adalimumab + MTX $(n=328)$} \\
\hline & GC $(n=161)$ & No-GC $(n=\mathbf{1 5 6})$ & GC $(\boldsymbol{n}=\mathbf{1 6 2})$ & No-GC $(n=164)$ \\
\hline Age, years & $50.5(12.7)$ & $52.4(12.5)$ & $49.2(12.1)$ & $52.9(13.0)$ \\
\hline Female sex, $n(\%)$ & $136(84.5)$ & $122(78.2)$ & $129(79.6)$ & $139(84.8)$ \\
\hline Disease duration, years & $2.0(1.4)$ & $1.8(1.4)$ & $2.0(1.4)$ & $1.5(1.3)$ \\
\hline Physical function (HAQ-DI) & $1.6(0.7)$ & $1.4(0.6)$ & $1.5(0.7)$ & $1.4(0.7)$ \\
\hline Number of patients, na & 146 & 148 & 147 & 148 \\
\hline mTSS & $23.0(36.6)$ & $15.6(27.1)$ & $23.1(62.7)$ & $14.8(22.4)$ \\
\hline ESS & $11.9(19.1)$ & $8.7(15.9)$ & $12.1(17.1)$ & $8.9(13.2)$ \\
\hline NSS & $11.1(18.5)$ & $6.9(12.4)$ & $11.0(17.6)$ & $6.0(10.6)$ \\
\hline CRP, mg/dL & $2.0(2.6)$ & $1.2(1.3)$ & $1.5(1.6)$ & $1.5(3.7)$ \\
\hline DAS28 (CRP) & $5.7(1.1)$ & $5.3(1.2)$ & $5.6(1.1)$ & $5.5(1.1)$ \\
\hline MTX dose, mg/week & $18.1(7.9)$ & $16.9(4.0)$ & $17.2(3.8)$ & $17.5(7.9)$ \\
\hline GC dose, mg/day & $6.6(2.6)$ & N/A & $6.6(2.3)$ & N/A \\
\hline Anti-CCP2 positive, $n(\%)$ & $70(43.5)$ & $73(46.8)$ & $62(38.3)$ & $91(55.5)$ \\
\hline RF positive, $n(\%)$ & $124(77.0)$ & $115(73.7)$ & $133(82.1)$ & $120(73.2)$ \\
\hline
\end{tabular}

Data from patients included in the AMPLE study $(\mathrm{N}=646)$, by treatment and GC use. Data are mean (SD) unless stated otherwise. GC administered at $\leq 10 \mathrm{mg}$ /day. All randomized and treated patients were included in the analysis. Number of patients with both baseline and postbaseline X-ray score (van der Heijde modified Sharp scoring system). CCP2: cyclic citrullinated peptide antibody-2; CRP: C-reactive protein; DAS28 (CRP): Disease Activity Score in 28 joints (C-reactive protein); ESS: erosion Sharp score; GC: glucocorticoid; HAQ-DI: Health Assessment Questionnaire-Disability Index; mTSS: modified total Sharp score; MTX: methotrexate; N/A: not applicable; no-GC: no glucocorticoid; NSS: joint space narrowing Sharp score; RF: rheumatoid factor; SC: subcutaneous; SD: standard deviation. 


\subsection{Clinical and Functional Evolution}

Adjusted mean change $(95 \% \mathrm{CI})$ from baseline to Years 1 and 2 in DAS28 (CRP) and HAQ-DI are shown in Table A1. There was no difference in improvement (adjusted mean change ( $95 \% \mathrm{CI}$ ) from baseline) in DAS28 (CRP) between the GC and no-GC subgroups in either the abatacept or adalimumab treatment arms at each time point. The adjusted mean change $(95 \% \mathrm{CI})$ from baseline in HAQ-DI was significantly greater in the adalimumab/GC subgroup than in the adalimumab/no-GC subgroup at Year $1(-0.75(-0.85,-0.65)$ vs. $-0.59(-0.69,-0.49) ; p=0.0188)$, but not at Year 2 , and did not differ significantly by GC treatment in abatacept-treated patients.

At Year 2, the proportions of patients in CDAI or SDAI remission or with DAS28 (CRP) $<2.6$ or HAQ-DI $\geq 0.3$ were similar in the GC and no-GC subgroups for both treatments irrespective of background GC use (Figure 1).
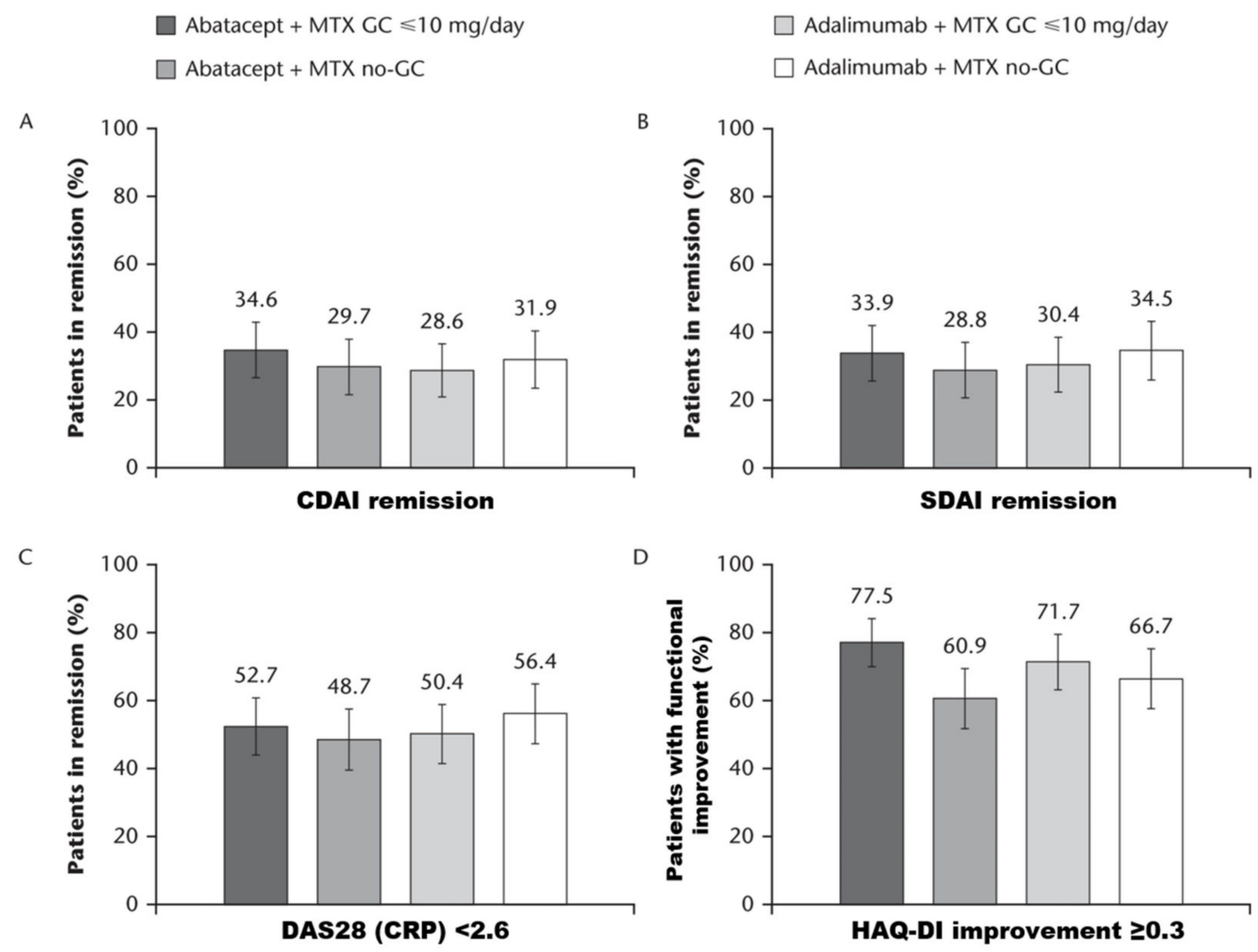

Figure 1. Clinical outcomes at Year 2. Proportion of patients ( $95 \% \mathrm{CI})$ achieving (A) CDAI remission, (B) SDAI remission, (C) DAS28 (CRP) $<2.6$, or (D) HAQ-DI improvement $\geq 0.3$ at Year 2 in abatacept + MTX or adalimumab + MTX GC ( $\leq 10 \mathrm{mg} /$ day $)$ and no-GC subgroups. CDAI remission defined as CDAI $\leq 2.8$; SDAI remission defined as $\leq 3.3$. CDAI: Clinical Disease Activity Index; CI: confidence interval; DAS28 (CRP): Disease Activity Score in 28 joints (C-reactive protein); GC: glucocorticoid; HAQ-DI: Health Assessment Questionnaire-Disability Index; MTX: methotrexate; no-GC: no glucocorticoid; SDAI: Simplified Disease Activity Index.

\subsection{Radiographic Evolution}

For both abatacept and adalimumab, there were no statistically significant differences between the background GC and no-GC subgroups either in mean change from baseline in mTSS at Years 1 and 2 (Table 2), or in the proportion of patients without radiographic progression in total Sharp score (TSS; smallest detectable change (SDC) criteria) at Years 1 and 2 (Table A2). There were numerical, but not statistically significant, differences in the proportion of patients without radiographic progression in TSS (SDC criteria) at Years 1 and 2 in favor of the no-GC subgroup (Table A2). 
Table 2. Change in modified total Sharp score from baseline at Years 1 and $2^{\mathrm{a}}$.

\begin{tabular}{|c|c|c|c|c|}
\hline & \multicolumn{2}{|c|}{ SC Abatacept + MTX $(n=318)$} & \multicolumn{2}{|c|}{ SC Adalimumab + MTX $(n=328)$} \\
\hline & GC $(n=161)$ & No-GC $(n=156)$ & GC $(n=162)$ & No-GC $(n=164)$ \\
\hline \multicolumn{5}{|l|}{ Year 1} \\
\hline \multicolumn{5}{|l|}{ Total score } \\
\hline$n$ & 146 & 148 & 147 & 148 \\
\hline Baseline mean (SD) & $23.02(36.64)$ & $15.61(27.11)$ & $23.07(32.65)$ & $14.83(22.42)$ \\
\hline Mean change from baseline (SD) & $0.88(2.90)$ & $0.24(2.28)$ & $1.43(9.06)$ & $0.03(2.09)$ \\
\hline Difference from no-GC $(95 \% \mathrm{CI})$ & $0.67(0.07,1.27)$ & N/A & $1.08(-0.42,2.58)$ & N/A \\
\hline \multicolumn{5}{|l|}{ Erosion score } \\
\hline$n$ & 146 & 148 & 147 & 148 \\
\hline Baseline mean (SD) & $11.93(19.09)$ & $8.67(15.93)$ & $12.05(17.11)$ & $8.85(13.23)$ \\
\hline Mean change from baseline (SD) & $0.27(1.87)$ & $0.14(1.76)$ & $0.57(5.12)$ & $-0.09(1.66)$ \\
\hline Difference from no-GC (95\% CI) & $0.17(-0.24,0.59)$ & N/A & $0.59(-0.28,1.47)$ & N/A \\
\hline \multicolumn{5}{|l|}{ Joint space narrowing score } \\
\hline$n$ & 146 & 148 & 147 & 148 \\
\hline Baseline mean (SD) & $11.10(18.54)$ & $6.94(12.35)$ & $11.02(17.60)$ & $5.98(10.58)$ \\
\hline Mean change from baseline (SD) & $0.62(2.14)$ & $0.09(0.95)$ & $0.86(4.17)$ & $0.12(0.94)$ \\
\hline Difference from no-GC (95\% CI) & $0.49(0.11,0.88)$ & N/A & $0.53(-0.16,1.22)$ & N/A \\
\hline \multicolumn{5}{|l|}{ Year 2} \\
\hline \multicolumn{5}{|l|}{ Total score } \\
\hline$n$ & 130 & 127 & 134 & 124 \\
\hline Baseline mean (SD) & $21.56(33.49)$ & $15.42(28.25)$ & $22.82(31.08)$ & $14.00(21.37)$ \\
\hline Mean change from baseline (SD) & $1.25(4.82)$ & $0.52(3.26)$ & $1.88(11.51)$ & $0.22(3.47)$ \\
\hline Difference from no-GC (95\% CI) & $0.75(-0.27,1.77)$ & N/A & $1.17(-0.95,3.29)$ & N/A \\
\hline \multicolumn{5}{|l|}{ Erosion score } \\
\hline$n$ & 130 & 127 & 134 & 124 \\
\hline Baseline mean (SD) & $11.30(17.03)$ & $8.81(16.77)$ & $12.09(17.22)$ & $8.43(12.14)$ \\
\hline Mean change from baseline (SD) & $0.49(2.56)$ & $0.32(2.58)$ & $0.75(6.65)$ & $-0.01(2.26)$ \\
\hline Difference from no-GC (95\% CI) & $0.21(-0.42,0.84)$ & N/A & $0.63(-0.61,1.87)$ & N/A \\
\hline \multicolumn{5}{|l|}{ Joint space narrowing score } \\
\hline$n$ & 130 & 127 & 134 & 124 \\
\hline Baseline mean (SD) & $10.26(17.31)$ & $6.61(12.53)$ & $10.74(15.80)$ & $5.58(10.52)$ \\
\hline Mean change from baseline (SD) & $0.75(2.87)$ & $0.20(1.05)$ & $1.13(5.05)$ & $0.23(1.51)$ \\
\hline Difference from no-GC $(95 \% \mathrm{CI})$ & $0.53(-0.01,1.07)$ & N/A & $0.60(-0.32,1.53)$ & N/A \\
\hline
\end{tabular}

a All randomized and treated patients. GC administered at $\leq 10 \mathrm{mg} /$ day. CI: confidence interval; GC: glucocorticoid;

MTX: methotrexate; N/A: not applicable; no-GC: no glucocorticoid; SC: subcutaneous; SD: standard deviation.

\subsection{Safety}

Adverse events (AEs) during follow-up are shown in Table 3. Two deaths occurred during the study (1 abatacept/no-GC; 1 adalimumab/GC), which were reported previously [8,9].

The abatacept/GC subgroup AE profile was similar compared with the abatacept/no-GC subgroup, with only small numerical, questionably clinically significant reductions in the incidences of major cardiovascular ( $5.0 \%$ vs. $6.4 \%$ ) and autoimmune (3.1\% vs. $4.5 \%)$ events, respectively. This was also true in the adalimumab/GC subgroup compared with the adalimumab/no-GC subgroup, with a small, questionably clinically significant numerical increase in the incidence of infectious serious AEs (SAEs) $(6.8 \%$ vs. $4.9 \%)$ and major cardiovascular events ( $4.9 \%$ vs. $3.0 \%)$, but with fewer local injection-site reactions $(6.8 \%$ vs. $14.0 \%)$. Although the incidences of malignancies were numerically lower with GC versus no-GC in both treatment groups, the numbers of events were very small.

In the abatacept/GC versus adalimumab/GC subgroups, there was a similar percent of SAEs (13.7\% vs. $15.4 \%)$, but numerically fewer discontinuations due to SAEs (1.2\% vs. $4.9 \%)$ and infectious SAEs $(3.7 \%$ vs. $6.8 \%)$, respectively. Similar incidences of major cardiovascular events ( $5.0 \%$ vs. $4.9 \%)$ and malignancies (1.9\% vs. $1.2 \%)$, more autoimmune events (3.1\% vs. $1.9 \%)$ and fewer local injection-site reactions ( $4.3 \%$ vs. $6.8 \%$ ) were reported in the abatacept/GC versus adalimumab/GC subgroup, respectively. 
In the abatacept/no-GC versus adalimumab/no-GC subgroups, there were numerically fewer discontinuations due to SAEs (1.9\% vs. $4.9 \%$ ) and infectious SAEs (3.8\% vs. $4.9 \%)$, more autoimmune events (4.5\% vs. $1.2 \%)$ and fewer local injection-site reactions (3.8\% vs. $14.0 \%)$.

Table 3. Summary of patients with adverse events reported over 2 years.

\begin{tabular}{|c|c|c|c|c|c|c|}
\hline \multirow{2}{*}{$\begin{array}{l}\text { System Organ Class, } \\
n(\%)\end{array}$} & \multicolumn{2}{|c|}{ SC Abatacept + MTX $(n=318)$} & \multirow[t]{2}{*}{$p$ Value } & \multicolumn{2}{|c|}{ SC Adalimumab $+\operatorname{MTX}(n=328)$} & \multirow[t]{2}{*}{$p$ Value } \\
\hline & GC $(n=161)$ & No-GC $(n=156)$ & & GC $(n=162)$ & No-GC $(n=164)$ & \\
\hline Deaths & 0 & $1(0.6)$ & 0.492 & $1(0.6)$ & 0 & 0.497 \\
\hline SAEs & $22(13.7)$ & $22(14.1)$ & 0.999 & $25(15.4)$ & $29(17.7)$ & 0.656 \\
\hline $\begin{array}{l}\text { Discontinued due } \\
\text { to SAEs }\end{array}$ & $2(1.2)$ & $3(1.9)$ & 0.681 & $8(4.9)$ & $8(4.9)$ & 1.000 \\
\hline Infectious SAEs & $6(3.7)$ & $6(3.8)$ & 1.000 & $11(6.8)$ & $8(4.9)$ & 0.488 \\
\hline $\begin{array}{l}\text { Major cardiovascular } \\
\text { events }\end{array}$ & $8(5.0)$ & $10(6.4)$ & 0.633 & $8(4.9)$ & $5(3.0)$ & 0.412 \\
\hline Malignancies & $3(1.9)$ & $4(2.6)$ & 0.720 & $2(1.2)$ & $5(3.0)$ & 0.448 \\
\hline Autoimmune events ${ }^{\text {a }}$ & $5(3.1)$ & $7(4.5)$ & 0.569 & $3(1.9)$ & $2(1.2)$ & 0.684 \\
\hline $\begin{array}{l}\text { Local injection-site } \\
\text { reactions }\end{array}$ & $7(4.3)$ & $6(3.8)$ & 1.000 & $11(6.8)$ & $23(14.0)$ & 0.045 \\
\hline
\end{tabular}

GC administered at $\leq 10 \mathrm{mg} /$ day. ${ }^{\text {a }}$ Excludes new autoantibody status (e.g., double-stranded DNA autoantibody positivity). GC: glucocorticoid; MTX: methotrexate; no-GC: no glucocorticoid; SAE: serious adverse event; SC: subcutaneous. $p$ value from Fisher exact test comparing GC vs. no-GC group in each arm.

\section{Discussion}

In biologic-naïve patients with active RA and an inadequate response to MTX who received abatacept or adalimumab, whether patients remained on stable GCs $(\leq 10 \mathrm{mg} /$ day $)$ started prior to baseline, or were not treated with GC during the study, had no detectable impact on clinical, functional or radiographic outcomes over two years. This confirms results of other reports with the same outcomes in the context of tofacitinib, tocilizumab, adalimumab and rituximab treatments [10-13,15-18]. In our current study (i) we showed similar results with a different bDMARD, i.e., abatacept, and (ii) we confirmed previous findings about adalimumab. Our observation should be related to the fact that in both groups, whether on background GC or not, patients still had active disease at baseline and the only modification to their therapy was the addition of abatacept or adalimumab, two effective therapies in RA.

A numerical trend toward a higher proportion of patients without radiographic progression in mTSS (SDC criteria) was observed at Years 1 and 2 in favor of the no-GC subgroup. However, these differences were small, unlikely to be clinically significant and may well be accounted for by higher baseline structural disease severity in patients on background GC compared with no-GC.

We identified some slight numerical differences between the GC and no-GC subgroups in terms of safety. However, the relevance of these differences was clinically questionable, except for local injection-site reactions which were less frequent in patients on background GC therapy in the adalimumab group. Given the post hoc nature of the study and the low number of events, the absence of statistical differences may be related to a lack of power. However, these differences are unlikely to be clinically meaningful.

There were significant limitations to this post hoc analysis. The numbers of patients in the GC and no-GC subgroups were small and these patient subgroups were not defined prospectively. Thus, the analysis was not statistically powered to detect differences between the GC and no-GC subgroups. In addition, this trial did not address the effectiveness of adding de novo GCs at $\leq 10 \mathrm{mg} /$ day to combination therapy with bDMARDs plus MTX in this patient population. Moreover, GCs were not tapered during Year 1 and patients had to remain on stable background GC therapy of $\leq 10 \mathrm{mg}$ throughout the trial, which is not in accordance with the rapid GC tapering mentioned in the 2019 update of the EULAR recommendations. In a real-life setting, GCs should be rapidly tapered and 
withdrawn in RA patients with inadequate response to MTX who are clinically and functionally improved after initiation of a bDMARD such as abatacept or adalimumab [2]. For these reasons, we cannot comment on whether there would have been a safety advantage or deleterious clinical consequences of an introduction or reduction of GC dose during the trial.

In RA patients with inadequate response to MTX on concomitant GC and continued active disease, initiating a treatment with abatacept or adalimumab was effective in improving clinical, functional and radiographic outcomes over two years with no meaningful differences from patients without background GC. Consistent with the 2019 EULAR recommendations, we would support GC tapering in RA patients reaching the therapeutic target. A well-designed, properly powered, prospective study is needed to definitively conclude on the efficacy and safety outcomes of low-dose oral GC tapering and discontinuation in patients reaching the therapeutic target under MTX and bDMARD combination.

Author Contributions: Conceptualization, Y.D., M.S., M.W., R.F., H.A.A. and A.C.; formal analysis, Y.D., M.S., M.W., R.F., H.A.A. and A.C.; investigation, M.S., M.W., R.F., H.A.A. and A.C.; writing-review and editing, Y.D., M.S., M.W., R.F., H.A.A. and A.C. All authors have read and agreed to the published version of the manuscript.

Funding: This study was funded by Bristol-Myers Squibb.

Acknowledgments: Professional medical writing and editorial assistance was provided by Claire Line and Sean Sheffler-Collins at Caudex and was funded by Bristol-Myers Squibb.

Conflicts of Interest: YD: reports receiving research grants from Pfizer and Celgene, and consulting fees from Bristol-Myers Squibb and Eli Lilly. MS: reports receiving consulting fees from AbbVie, Bristol-Myers Squibb, Eli Lilly, JNJ, and UCB; and speaker fees from AbbVie and Bristol-Myers Squibb. MW: reports receiving research grants from Amgen, Bristol-Myers Squibb, Crescendo Bioscience, UCB, and Sanofi; and consulting fees from Amgen, Bristol-Myers Squibb, Crescendo Bioscience, UCB, AbbVie, Lilly, Pfizer, and Roche. RF: reports receiving grant/research support from AbbVie, Amgen, Bristol-Myers Squibb, Janssen, Eli Lilly, Merck, Novartis, Pfizer, Roche, Samumed, Sanofi, and UCB; and consulting fees from AbbVie, Amgen, Bristol-Myers Squibb, GSK, Eli Lilly, Pfizer, Sanofi, and UCB. HAA: is an employee of Bristol-Myers Squibb. AC: reports receiving research grants from MSD, Pfizer, and UCB; and consulting fees from Amgen, AbbVie, BMS, Celgene, Gilead, Janssen, Lilly, Novartis, Pfizer, Sanofi, and UCB. The authors declare no conflict of interest.

\section{Appendix A}

Table A1. Adjusted mean change from baseline in DAS28 (CRP) and HAQ-DI at Years 1 and $2^{\text {a }}$.

\begin{tabular}{|c|c|c|c|c|}
\hline & \multicolumn{2}{|c|}{ SC Abatacept + MTX $(n=318)$} & \multicolumn{2}{|c|}{ SC Adalimumab + MTX $(n=328)$} \\
\hline & GC $(n=161)$ & No-GC $(n=156)$ & GC $(n=162)$ & No-GC $(n=164)$ \\
\hline \multicolumn{5}{|l|}{ DAS28 (CRP) } \\
\hline Year $1, n$ & 142 & 132 & 138 & 128 \\
\hline $\begin{array}{l}\text { Adjusted mean change from } \\
\text { baseline }(95 \% \mathrm{CI})\end{array}$ & $-2.52(-2.73,-2.31)$ & $-2.37(-2.58,-2.16)$ & $-2.59(-2.80,-2.38)$ & $-2.50(-2.71,-2.29)$ \\
\hline Estimate of difference $(95 \% \mathrm{CI})$ & $-0.14(-0.43,0.14)$ & N/A & $-0.09(-0.38,0.19)$ & N/A \\
\hline Year $2, n$ & 131 & 119 & 125 & 117 \\
\hline $\begin{array}{c}\text { Adjusted mean change from } \\
\text { baseline }(95 \% \text { CI })\end{array}$ & $-2.75(-2.99,-2.52)$ & $-2.55(-2.79,-2.31)$ & $-2.59(-2.82,-2.35)$ & $-2.62(-2.86,-2.39)$ \\
\hline Estimate of difference $(95 \% \mathrm{CI})$ & $-0.20(-0.52,0.12)$ & N/A & $0.04(-0.28,0.36)$ & N/A \\
\hline \multicolumn{5}{|l|}{ HAQ-DI } \\
\hline Year $1, n$ & 139 & 128 & 135 & 126 \\
\hline $\begin{array}{l}\text { Adjusted mean change from } \\
\text { baseline }(95 \% \mathrm{CI})\end{array}$ & $-0.72(-0.83,-0.62)$ & $-0.62(-0.72,-0.51)$ & $-0.75(-0.85,-0.65)$ & $-0.59(-0.69,-0.49)$ \\
\hline Estimate of difference $(95 \% \mathrm{CI})$ & $-0.11(-0.25,0.04)$ & N/A & $-0.17(-0.30,-0.03)$ & N/A \\
\hline Year $2, n$ & 129 & 115 & 120 & 108 \\
\hline $\begin{array}{l}\text { Adjusted mean change from } \\
\text { baseline }(95 \% \mathrm{CI})\end{array}$ & $-0.74(-0.85,-0.62)$ & $-0.64(-0.75,-0.53)$ & $-0.73(-0.84,-0.62)$ & $-0.61(-0.72,-0.50)$ \\
\hline Estimate of difference (95\% CI) & $-0.10(-0.25,0.06)$ & N/A & $-0.12(-0.27,0.03)$ & N/A \\
\hline
\end{tabular}

a All randomized and treated patients. GC administered at $\leq 10 \mathrm{mg} /$ day. CI: confidence interval; DAS28 (CRP):

Disease Activity Score in 28 joints (C-reactive protein); GC: glucocorticoid; HAQ-DI: Health Assessment

Questionnaire-Disability Index; MTX: methotrexate; N/A: not applicable; no-GC: no glucocorticoid; SC: subcutaneous. 
Table A2. Proportion of patients without radiographic progression in total Sharp score at Years 1 and $2^{\mathrm{a}}$.

\begin{tabular}{|c|c|c|c|c|}
\hline \multirow{2}{*}{ Change from Baseline $\leq$ SDC (2.2) } & \multicolumn{2}{|c|}{ SC Abatacept + MTX $(n=318)$} & \multicolumn{2}{|c|}{ SC Adalimumab + MTX $(n=328)$} \\
\hline & GC $(n=161)$ & No-GC $(n=156)$ & GC $(n=162)$ & No-GC $(n=164)$ \\
\hline \multicolumn{5}{|l|}{ Year 1} \\
\hline Number of patients, $n / \mathrm{N}(\%)$ & $123 / 146(84.25)$ & $135 / 148(91.22)$ & $125 / 147(85.03)$ & $137 / 148(92.57)$ \\
\hline $95 \%$ CI & $78.34,90.16$ & $86.66,95.78$ & $79.27,90.80$ & $88.34,96.79$ \\
\hline Estimate of difference $(95 \% \mathrm{CI})$ & $-7.0(-15.1,1.2)$ & N/A & $-7.5(-15.4,0.3)$ & N/A \\
\hline \multicolumn{5}{|l|}{ Year 2} \\
\hline Number of patients, n/N (\%) & $105 / 130(80.77)$ & $113 / 127(88.98)$ & 107/134 (79.85) & $110 / 124(88.71)$ \\
\hline $95 \% \mathrm{CI}$ & $73.99,87.54$ & $83.53,94.42$ & $73.06,86.64$ & $83.14,94.28$ \\
\hline Estimate of difference (95\% CI) & $-8.2(-17.7,1.3)$ & N/A & $-8.9(-18.4,0.7)$ & N/A \\
\hline
\end{tabular}

Progression in total Sharp score definition is based on the smallest detectable change (SDC) criterion. ${ }^{\text {a }}$ All randomized and treated patients. GC administered at $\leq 10 \mathrm{mg} /$ day. CI: confidence interval; GC: glucocorticoid; $\mathrm{N}$ : number of patients with both baseline and postbaseline X-ray total score based on imputed data; MTX: methotrexate; N/A: not applicable; no-GC: no glucocorticoid; SC: subcutaneous; SDC: smallest detectable change.

\section{References}

1. Singh, J.A.; Saag, K.G.; Bridges, S.L.; Akl, E.A.; Bannuru, R.R.; Sullivan, M.C.; Vaysbrot, E.; McNaughton, C.; Osani, M.; Shmerling, R.; et al. 2015 American College of Rheumatology Guideline for the Treatment of Rheumatoid Arthritis. Arthritis Rheumatol. 2016, 68, 1-26. [CrossRef] [PubMed]

2. Smolen, J.S.; Landewé, R.B.M.; Bijlsma, J.W.J.; Burmester, G.R.; Dougados, M.; Kerschbaumer, A.; McInnes, I.B.; Sepriano, A.; Van Vollenhoven, R.F.; De Wit, M.; et al. EULAR recommendations for the management of rheumatoid arthritis with synthetic and biological disease-modifying antirheumatic drugs: 2019 update. Ann. Rheum. Dis. 2020, 79, 685-699. [CrossRef] [PubMed]

3. Strehl, C.; Bijlsma, J.W.J.; De Wit, M.; Boers, M.; Caeyers, N.; Cutolo, M.; Dasgupta, B.; Dixon, W.G.; Geenen, R.; Huizinga, T.W.J.; et al. Defining conditions where long-term glucocorticoid treatment has an acceptably low level of harm to facilitate implementation of existing recommendations: Viewpoints from an EULAR task force. Ann. Rheum. Dis. 2016, 75, 952-957. [CrossRef] [PubMed]

4. Palmowski, Y.; Buttgereit, T.; Dejaco, C.; Bijlsma, J.W.; Matteson, E.L.; Voshaar, M.; Boers, M.; Buttgereit, F. "Official View" on Glucocorticoids in Rheumatoid Arthritis: A Systematic Review of International Guidelines and Consensus Statements. Arthritis Rheum. 2017, 69, 1134-1141. [CrossRef] [PubMed]

5. Mahajan, T.; O'Dell, J.R. It is the Best of Treatments, it is the Worst of Treatments: The Continuing Love-Hate Relationship with Glucocorticoids in Rheumatoid Arthritis. Arthritis Rheum. 2017, 69, 1131-1133. [CrossRef] [PubMed]

6. Buttgereit, F.; Bijlsma, J.W. Glucocorticoids in rheumatoid arthritis: The picture is shaping up. Ann. Rheum. Dis. 2017, 76, 1785-1787. [CrossRef] [PubMed]

7. Chatzidionysiou, K.; Emamikia, S.; Nam, J.; Ramiro, S.; Smolen, J.; Van Der Heijde, D.; Dougados, M.; Bijlsma, J.; Burmester, G.; Scholte, M.; et al. Efficacy of glucocorticoids, conventional and targeted synthetic disease-modifying antirheumatic drugs: A systematic literature review informing the 2016 update of the EULAR recommendations for the management of rheumatoid arthritis. Ann. Rheum. Dis. 2017, 76, 1102-1107. [CrossRef] [PubMed]

8. Weinblatt, M.E.; Schiff, M.; Valente, R.; Van Der Heijde, D.; Citera, G.; Zhao, C.; Maldonado, M.; Fleischmann, R. Head-to-head comparison of subcutaneous abatacept versus adalimumab for rheumatoid arthritis: Findings of a phase IIIb, multinational, prospective, randomized study. Arthritis Rheum. 2012, 65, 28-38. [CrossRef] [PubMed]

9. Schiff, M.; Weinblatt, M.E.; Valente, R.; Van Der Heijde, D.; Citera, G.; Elegbe, A.; Maldonado, M.; Fleischmann, R. Head-to-head comparison of subcutaneous abatacept versus adalimumab for rheumatoid arthritis: Two-year efficacy and safety findings from AMPLE trial. Ann. Rheum. Dis. 2013, 73, 86-94. [CrossRef] [PubMed] 
10. Charles-Schoeman, C.; Van Der Heijde, D.; Burmester, G.R.; Nash, P.; Zerbini, C.A.; Connell, C.A.; Fan, H.; Kwok, K.; Bananis, E.; Fleischmann, R. Effect of Glucocorticoids on the Clinical and Radiographic Efficacy of Tofacitinib in Patients with Rheumatoid Arthritis: A Posthoc Analysis of Data from 6 Phase III Studies. J. Rheumatol. 2017, 45, 177-187. [CrossRef] [PubMed]

11. Fleischmann, R.; Wollenhaupt, J.; Cohen, S.; Smolen, J.S.; Dahl, P.; Iikuni, N.; Shi, H.; Tatulych, S.; Takiya, L. SAT0247 Impact of glucocorticoids on efficacy and safety of tofacitinib with and without methotrexate and adalimumab with methotrexate for rheumatoid arthritis: Results from a phase 3b/4 randomised trial. Ann. Rheum. Dis. 2018, 77, 985-986. [CrossRef]

12. Fleischmann, R.; Wollenhaupt, J.; Cohen, S.; Wang, L.; Fan, H.; Bandi, V.; Andrews, J.; Takiya, L.; Bananis, E.; Weinblatt, M.E. Effect of Discontinuation or Initiation of Methotrexate or Glucocorticoids on Tofacitinib Efficacy in Patients with Rheumatoid Arthritis: A Post Hoc Analysis. Rheumatol. Ther. 2018, 5, $203-214$. [CrossRef] [PubMed]

13. Safy-Khan, M.; Jacobs, J.W.G.; De Hair, M.J.H.; Welsing, P.M.J.; Edwardes, M.D.; Teitsma, X.M.; Luder, Y.; Devenport, J.; Van Laar, J.M.; Pethoe-Schramm, A.; et al. Effect on efficacy and safety trial outcomes of also enrolling patients on ongoing glucocorticoid therapy in rheumatoid arthritis clinical trials of tocilizumab or adalimumab or methotrexate monotherapy. Ann. Rheum. Dis. 2020, 79, 460-463. [CrossRef] [PubMed]

14. Bruynesteyn, K.; Boers, M.; Kostense, P.; Van Der Linden, S.; Van Der Heijde, D. Deciding on progression of joint damage in paired films of individual patients: Smallest detectable difference or change. Ann. Rheum. Dis. 2004, 64, 179-182. [CrossRef] [PubMed]

15. Jones, G.; Sebba, A.; Gu, J.; Lowenstein, M.B.; Calvo, A.; Gomez-Reino, J.J.; Siri, D.A.; Tomšič, M.; Alecock, E.; Woodworth, T.; et al. Comparison of tocilizumab monotherapy versus methotrexate monotherapy in patients with moderate to severe rheumatoid arthritis: The AMBITION study. Ann. Rheum. Dis. 2009, 69, 88-96. [CrossRef] [PubMed]

16. Gabay, C.; Emery, P.; Van Vollenhoven, R.; Dikranian, A.; Alten, R.; Pavelka, K.; Klearman, M.; Musselman, D.; Agarwal, S.; Green, J.; et al. Tocilizumab monotherapy versus adalimumab monotherapy for treatment of rheumatoid arthritis (ADACTA): A randomised, double-blind, controlled phase 4 trial. Lancet 2013, 381, 1541-1550. [CrossRef]

17. Dougados, M.; Kissel, K.; Sheeran, T.; Tak, P.P.; Conaghan, P.G.; Mola, E.M.; Schett, G.; Amital, H.; Navarro-Sarabia, F.; Hou, A.; et al. Adding tocilizumab or switching to tocilizumab monotherapy in methotrexate inadequate responders: 24-week symptomatic and structural results of a 2-year randomised controlled strategy trial in rheumatoid arthritis (ACT-RAY). Ann. Rheum. Dis. 2012, 72, 43-50. [CrossRef] [PubMed]

18. Burmester, G.R.; Rigby, W.F.; Van Vollenhoven, R.F.; Kay, J.; Rubbert-Roth, A.; Blanco, R.; Kadva, A.; Dimonaco, S. Tocilizumab combination therapy or monotherapy or methotrexate monotherapy in methotrexate-naive patients with early rheumatoid arthritis: 2-year clinical and radiographic results from the randomised, placebo-controlled FUNCTION trial. Ann. Rheum. Dis. 2017, 76, 1279-1284. [CrossRef] [PubMed]

(C) 2020 by the authors. Licensee MDPI, Basel, Switzerland. This article is an open access article distributed under the terms and conditions of the Creative Commons Attribution (CC BY) license (http://creativecommons.org/licenses/by/4.0/). 